\title{
Poor sleep is associated with sensation-seeking and risk behavior in college students
}

Laila Taghvaee ${ }^{1}$

Amir Ali Mazandarani2*

${ }^{1}$ Islamic Azad University, Psychology Tehran - Tehran - Iran.

${ }^{2}$ The Institute for Research and Development in the Humanities (SAMT), Behavioral Sciences - Tehran - Tehran Iran.

\begin{abstract}
Objective: The current study examines the relationship between sleep duration and variability with sensation- seeking and risky behaviors in a sample of Iranian undergraduate students. Methods: The participants in this study were 385 undergraduate students in Tehran. To collect data, we used the Sensation Seeking Scale, Risk Behavior Scale, and two questions related to sleep duration and sleep variability. Results: The results showed a positive relationship between sleep deprivation and irregular sleep schedule with sensation-seeking and risk behavior tendencies in students. Discussion: This association could point to an indirect impact of sleep deprivation on sensationseeking and risk behavior, for example, by altering brain regions responsible for self- control.
\end{abstract}

Keywords: Risk-Taking; Sleep Deprivation; Sensation.
*Corresponding author:

Amir Ali Mazandarani

E-mail: mazandarani@live.com /

Mazandaraniaa@gmail.com

Received: May 25, 2021;

Accepted: August 20, 2021.

DOI: 10.5935/1984-0063.20220024 


\section{INTRODUCTION}

Sensation-seeking and risk-taking propensities are prevalent in young adulthood ${ }^{1}$ and may have lifelong negative consequences. Sensation seeking is associated with alcohol use ${ }^{2}$ and aggression ${ }^{3}$, and risky behaviors may lead to motor vehicle crashes, homicide, and suicide, which are the leading causes of death for all young people aged 18 to 24 years ${ }^{4}$. It seems that one of the factors affecting sensation-seeking tendencies and risk-taking behaviors is sleep problems.

Sleep deprivation refers to having less than the recommended amount of sleep, which for adults is between seven and nine hours a night ${ }^{5}$. Sleep deprivation is a severe and rising issue in modern society, especially among university students, and the number of students who are routinely sleep-deprived due to increasing psycho-social stresses. Most college students are sleep deprived, with 70.6 percent reporting getting less than 8 hours of sleep a night. Their sleep schedule is also irregular. They tend to delay both bedtimes and rise times at weekends. Furthermore, university students suffer from poor sleep quality ${ }^{6,7}$. Due to the negative impacts of insufficient and irregular sleep schedules on physical and mental health, the widespread prevalence of sleep problems among students can be considered a significant public health problem.

Sensation seeking is a personality trait characterized by a generalized preference for diverse, novel, complex, and intense sensations and experiences, as well as a desire to take risks to achieve those experiences ${ }^{8}$. There has been limited research on the link between poor sleep and sensation-seeking predisposition. For example, Killgore ${ }^{9}$ demonstrated that one night of sleep deprivation decreased self-reported sensation-seeking significantly. He explained his observation by claiming that sleep deprivation is associated with significant physical and mental exhaustion, as well as a sense of diminished energy and vigor, and the majority of the items on the Sensation-Seeking Scale necessitate some level of energy expenditure. in other studies ${ }^{10,11}$, high sensationseeking was unrelated to insomnia severity and sleep length.

In addition, high levels of sensation-seeking may have advantages. High sensation seekers, for example, respond better to external stressors like violence and captivity than low sensation seekers ${ }^{12}$. As a result, they also could be more resistant to the stress of poor sleep. In a recent study, McGowan and her colleagues 13 found that in comparison to days after average and poor sleep quality, momentary sensation-seeking peaks higher and earlier after nights with better sleep quality. They concluded that sleep quality could help people search out new experiences in everyday life without rash decisions.

In converse, in a study by Rusnac, Spitzenstetter, and Tassi ${ }^{14}$, sleep deprivation was associated with increased sensation-seeking, mainly when the sleep deprivation was voluntary. In addition, in several studies, university students with an evening circadian preference score higher than those with a morning preference on the Sensation-Seeking ${ }^{15}$, and when compared to morning types, evening types have more inferior sleep quality and shorter sleep length ${ }^{16}$. High levels of sensation-seeking are also linked to various adverse outcomes, including higher levels of risk-taking ${ }^{17}$.

Sleep loss, both chronic and acute, is related to increased reward sensitivity and risk-taking in adults 18 and adolescents ${ }^{19}$. According to a large-scale analysis of military service members ${ }^{20}$, longer sleep time decreases the likelihood of risk-taking behaviors and predicts a lower chance of committing any high-risk behavior. The effect of sleep loss on increased risk-taking may be due to several underlying cognitive mechanisms, including inattention or attentional lapses, lack of awareness of actual sleepiness and impairments caused by it, and insufficient inhibitory control. Therefore, sleep loss can also increase risk by reducing inhibitory capacity. Furthermore, when gains are emphasized, sleep deprivation leads to a greater willingness to take risks. ${ }^{21}$.

Sleep deprivation can alter behavioral, cognitive, and emotional factors that increase risk-taking ${ }^{22}$. Sleep loss temporarily alters brain function, especially in areas in the prefrontal cortex, most responsible for selfregulation. According to preliminary research ${ }^{23}$, the neurophysiological changes caused by prolonged sleep deprivation may even trigger novel manic-psychotic episodes. Some of these changes can affect cognitive functions, enhancing the propensity to participate in risky behaviors. Sleep deprivation has been attributed to impulsivity as well as alterations in reward-related decision-making ${ }^{24}$. According to a recent study, five nights of partial sleep deprivation decreased data collection before making decisions and increased risk-taking more than after one night of complete sleep deprivation ${ }^{25}$. Since many students in Iran are chronically and partially sleep deprived ${ }^{7}$, this result has unique implications for public health policy and practice in Iran.

Research to date has often shown conflicting findings on the complex relationship between sleep indices with sensation-seeking and risk-taking propensities. In one study ${ }^{26}$, poor sleep was linked to more reckless driving. However, good sleep was protection against risky driving in adolescents who had less sensation-seeking tendencies. Therefore, Sensation-seeking may moderate the relation between poor sleep and risk behavior. Data from a study of adolescents and young adults ${ }^{27}$ showed that sleep duration and delayed bedtimes are associated with delinquent behavior. These effects are mediated by sensation-seeking and impulse control. Similarly, research ${ }^{28}$ has shown that regardless of sleep adequacy, sensation-seeking is associated with higher alcohol intake by young adults. In contrast, premeditation is only protective against binge drinking in people who get sufficient sleep. 
Most research on the connection between sleep and sensation-seeking and high-risk behaviors has concentrated on sleep deprivation, with little attention given to sleep schedule variability. The present research, however, aims to investigate the relationship between both sleep length and variability with sensation-seeking and risk behavior. We hypothesize that both partial sleep deprivation and irregular sleep schedule would be associated with sensation-seeking and risk behavior.

\section{MATERIAL AND METHODS}

We used a descriptive cross-sectional approach to assess the association between sleep deprivation and irregular sleep with sensation-seeking and risk behaviors in students. The study was reviewed and approved by the ethics committee of Soore University in Tehran.

\section{Participants}

During Stay-at-Home orders and since university classes were only held online due to the COVID-19 outbreak, a link to a form containing the study instruments was sent to major student social media groups at three universities in Tehran between July 13, 2020, and January 10,2021 . Overall, the forms were entirely completed by 385 undergraduate students. We designed the form so that responses to all items were mandatory, so there was no missing data or an incomplete form. The students' ages ranged from 18 to 30 years $(M=23.37$; $S D=3.7$; $68.6 \%$ were female; and $82.3 \%$ were single).

\section{Statistical Procedures}

For statistical procedures, we used IBM SPSS 26. Depending on the types of variables, we calculated Pearson, biserial, and phi correlation coefficients and then assessed their statistical significance. For betweengroup comparisons, we used several two-way analyses of variances to determine the interactive effect of sleep duration and variation. We conducted many statistical tests, therefore, we needed to control for multiple testing. All P-values were adjusted based on BenjaminiHochberg's correction for decreasing the false discovery rate ${ }^{29}$. To do this, we used a syntax available on the IBM website ${ }^{30}$. To determine effect sizes, partial eta-squared was used, with small, medium, and large effects defined as $.01, .06$, and .14 or higher, respectively ${ }^{31}$.

\section{Research Instruments}

\section{Sensation Seeking Scale Form- $\mathbf{V}^{32}$}

To assess individual differences in trait sensationseeking, we chose the Persian version of Zuckerman's SSS, adapted by Mahvi-Shirazi ${ }^{33}$. The SSS consists of 40 items and four subscales with ten items each: disinhibition (DIS), boredom susceptibility (BS), thrill and adventure- seeking (TAS), and experience seeking (ES). We asked participants to choose one of two alternative descriptions for each item. Based on their choices, items were coded as 0 or 1 and then summed to obtain the total SSS score and the four scale scores. The reliability and validity of SSS are confirmed in different countries ${ }^{34,35}$. In the present study, the overall SSS score and three out of the four subscales showed satisfactory internal consistency $(\alpha=.97$ for DIS; $\alpha=.66$ for BS; $\alpha=.77$ for TAS; $\alpha=.92$ for ES, and $\alpha=$ .92 for overall SSS).

\section{Risk Behaviors Scale ${ }^{36}$}

We assessed high-risk behaviors using the Risk Behaviors Scale. The scale's items explore the prevalence of high-risk behaviors in the context of Iran's cultural and social constraints. This questionnaire contained 61 items, with responses ranging from 0 to 4 on a 5 -point Likert scale. According to Shafiee ${ }^{36}$, experts and professors supported the content validity of the scale. To assess construct validity in this research, we used exploratory factor analysis with the Principal Component approach and Varimax rotation. Following factor analysis, we omitted 16 poor items (items with cross-loading or loading less than 0.5). After we removed the unreliable items, The Kaiser-Mayer-Olkin coefficient (.97) was excellent, and the Bartlett test of sphericity coefficient was $\mathrm{X}_{\text {approx }}^{2}=17,733.20, \mathrm{P}<0.0001$, implying adequate factors can be derived from the data. The second exploratory factor analysis with the same method on the remaining 45 items resulted in a five factors solution with eigenvalues greater than 1 ( $\alpha=.970$ for overall scale): Violence, drug use, and HIV risk (19 items; $\alpha=.97$ ), Tobacco and Alcohol Experiences (10 items; $\alpha=.95$ ), anger and family conflicts ( 8 items; $\alpha=.92)$, Unhealthy diet (6 items; $\alpha=.87$ ), and overweight and dieting (2 items; $\alpha=0.75$ ). These five factors explained $51.47 \%$ of the total variance in the data. For more details about the Risk Behavior Scale and its factors, items, and loadings, see the Appendix at the end of the current article. In the present study, the participants' overall score on this scale positively correlated with their overall score on the SSS (Pearson's correlation coefficient $=0.7$ ) .

\section{Sleep Duration and Variability}

Sleep duration and variability were measured by two single items: "How many hours of sleep per 24 hours do you normally get?" In the present study, in line with many other studies ${ }^{37}$, laboratory studies ${ }^{38}$, and public opinion ${ }^{39}$, the criterion for partial sleep deprivation was considered as sleeping less than 6 hours a day. We split participants into two groups: those who typically sleep 6 hours or more and those who sleep less than 6 hours a day. In several studies ${ }^{27}$, researchers have used a similar question to measure sleep duration. Also, sleep variability was measured by a single item asking students to rate their agreement with the statement, "My sleep schedule is irregular" by choosing "yes" or " no". There is still no clear definition of sleep variability, nor is 
there any research-based recommendation to determine how much variation in sleep timing is desirable ${ }^{40}$. Therefore, we provided this definition in the questionnaire so that participants would understand what we meant by irregular sleep schedule: "By sleep irregularity, we imply a difference of more than two hours between bedtimes and/or rising-times on weekdays and weekends." Research ${ }^{41,42}$ has confirmed a moderate concurrent validity of these kinds of self-reported subjective measures by showing high agreement between subjective and objective measures of sleep.

\section{RESULTS}

Only 73 students (19\%) reported that, on average, they slept less than 6 hours a night. However, 223 participants $(57.9 \%)$ reported having irregular sleep patterns during the weekdays.

\section{Correlations}

Table 1, shows the means, standard deviations, and correlations between the research variables. Sleep deprivation and variability were positively correlated to sensation-seeking and risk behavior and all but one of their sub-scales $(\mathrm{P}<.01)$. However, all the coefficient values were moderate to low. Specifically, reported sleep deprivation was moderately correlated with sensation seeking $(\mathrm{r}=.39$; $\mathrm{P}<.001$ ), and slightly correlated with risk behavior scores $(\mathrm{r}=.26 ; \mathrm{P}<.001)$. Also, reported sleep variability was moderately correlated with sensation seeking $(\mathrm{r}=.49 ; \mathrm{P}<$ $.001)$ and risk behavior scores $(\mathrm{r}=.39 ; \mathrm{P}<.001)$.

\section{Between-group comparisons}

We conducted 11 two-way ANOVAs to examine the combined effects of sleep duration (less than 6 hours vs. 6 hours and more) and sleep variability (irregular vs. regular sleep schedule) on sensation seeking and risk behavior and their subscales. As shown in Table 2, The interactive effect of sleep duration and sleep variability on overall sensation-seeking was significant $(\mathrm{P}<.05$; partial $\left.\eta^{2}=.016\right)$. The interactive effect was also significant for disinhibition subscale $\left(\mathrm{P}<.05\right.$; partial $\left.\eta^{2}=.016\right)$. The interactive effect of sleep duration and sleep variability on overall risk behavior was not significant. However, the combined effect on Anger and family conflicts was significant $\left(\mathrm{P}<.05\right.$; partial $\left.\eta^{2}=.012\right)$.

According to the principle of marginality, we do not report the main effects in the presence of interaction effects. The main effects of sleep duration on the other three sensation-seeking subscales (i.e. Boredom Susceptibility, Thrill and Adventure Seeking, and Experience Seeking) were significant ( $\mathrm{Ps}<.01$; partial $\eta^{2} \mathrm{~s}=.093, .076$, and .108 respectively). In other words, students who reported sleeping less than 6 hours a night scored higher on the three sensation-seeking sub-scales. The main effect of sleep duration on overall risk behavior score was also significant $(\mathrm{P}<$ .01 ; partial $\eta 2=.039$ ). Finally, the main effects of sleep duration on the other four risk-behavior subscales (i.e. Violence, Drug Use, and HIV Risk, Tobacco and Alcohol Experiences, Unhealthy diet, and Overweight and dieting) were significant (Ps for first two $<.01$ and the second two < .05; partial $\eta^{2} s=.031, .026, .019$ and .014 respectively). In other words, students who reported sleeping less than 6 hours a night scored higher on the risk behavior scale and the four sub-scales mentioned.

Table 1. Means, standard deviations, and correlations between all variables $(\mathrm{n}=385)$.

\begin{tabular}{|c|c|c|c|c|c|c|c|c|c|c|c|c|c|c|}
\hline & $\mathbf{M}$ & SD & 1 & 2 & 3 & 4 & 5 & 6 & 7 & 8 & 9 & 10 & 11 & 12 \\
\hline 1. Disinhibition & 4.25 & 2.28 & & & & & & & & & & & & \\
\hline 2. Boredom Susceptibility & 3.94 & 2.84 & $.66^{* *}$ & & & & & & & & & & & \\
\hline 3. Thrill and Adventure Seeking & 5.00 & 3.75 & $.68^{* *}$ & $.65^{* *}$ & & & & & & & & & & \\
\hline 4. Experience Seeking & 4.27 & 2.66 & $.75^{* *}$ & $.78^{* *}$ & $.76^{* *}$ & & & & & & & & & \\
\hline 5. Sensation Seeking & 14.91 & 8.70 & $.83^{* *}$ & $.86^{* *}$ & $.91^{* *}$ & $.90 * *$ & & & & & & & & \\
\hline 6. Violence, Drug use, and HIV Risk & 7.99 & 13.70 & $.58 * *$ & $.62 * *$ & $.48^{* *}$ & $.62 * *$ & $.59 * *$ & & & & & & & \\
\hline 7. Tobacco and Alcohol Experiences & 10.89 & 10.77 & $.67 * *$ & $.62 * *$ & $.52 * *$ & $.65 * *$ & $.66 * *$ & $.76^{* *}$ & & & & & & \\
\hline 8. Anger and family conflicts & 9.59 & 7.33 & $.65^{* *}$ & $.54 * *$ & $.55^{* *}$ & $.66^{* *}$ & $.64 * *$ & $.69 * *$ & $.71^{* *}$ & & & & & \\
\hline 9. Unhealthy diet & 9.49 & 5.22 & $.53 * *$ & $.45^{* *}$ & $.46^{* *}$ & $.53 * *$ & $.53 * *$ & $.55^{* *}$ & $.62 * *$ & $.67^{* *}$ & & & & \\
\hline 10. Overweight and dieting & 1.31 & 1.83 & $.26 * *$ & .10 & $.21 * *$ & $.19 * *$ & $.20 * *$ & $.15^{*}$ & $.22 * *$ & $.34 * *$ & $.31 * *$ & & & \\
\hline 11. Risk behavior & 39.27 & 33.10 & $.70^{* *}$ & $.66^{* *}$ & $.58^{* *}$ & $.71 * *$ & $.70^{* *} *$ & $.91 * *$ & $.91 * *$ & $.86^{* *}$ & $.75^{* *}$ & $.32 * *$ & & \\
\hline 12. Sleep Deprivation & 1.19 & .39 & $.37 * *$ & $.36 * *$ & $.32 * *$ & $.38^{* *}$ & $.39 * *$ & $.24 * *$ & $.23^{* *}$ & $.22 * *$ & $.15^{*}$ & $.14^{*}$ & $.26^{* *}$ & \\
\hline 13. Sleep Variability & 1.58 & .49 & $.45^{* *}$ & $.38^{* *}$ & $.47^{* *}$ & $.44 * *$ & $.49 * *$ & $.29 * *$ & $.34 * *$ & $.41 * *$ & $.36 * *$ & $.21 * *$ & $.39 * *$ & $.21 * *$ \\
\hline
\end{tabular}

Sleep Deprivation and sleep Variability are dichotomous variables (i.e., no=1, yes $=2$ ); as a result, we calculated the correlation between them with the phi correlation coefficient, and we calculated their correlation with other variables by the biserial correlation. For other variables, we used the Pearson correlation coefficient. P-values are adjusted using Benjamini-Hochberg's method; * $\mathrm{P}<.01 ; * * \mathrm{P}<.001$ 
Table 2. Two-way ANOVA results on the influence of sleep duration, sleep variability, and interaction between sleep duration and sleep variability on sensation seeking and risk behavior and their subscales.

\begin{tabular}{|c|c|c|c|c|c|c|}
\hline & Scales Parameters & $\begin{array}{c}\text { Good-Sleepers }^{a} \\
\text { M (SD) }\end{array}$ & $\begin{array}{c}\text { Poor-Sleepers }^{\mathrm{b}} \\
\text { M (SD) }\end{array}$ & $\mathbf{F}^{\mathrm{C}}$ & Adjusted $P$-Values ${ }^{\mathrm{C}}$ & partial eta $^{2 \mathrm{C}}$ \\
\hline \multirow[t]{3}{*}{ Disinhibition } & Sleep Duration & $3.84(2.16)$ & $6.01(1.90)$ & 48.35 & $<.01$ & .113 \\
\hline & Sleep Variability & $3.05(1.75)$ & $5.13(2.22)$ & 17.74 & $<.01$ & .044 \\
\hline & Interaction & - & - & 6.08 & $<.05$ & .016 \\
\hline \multirow[t]{3}{*}{ Boredom Susceptibility } & Sleep Duration & $3.45(2.53)$ & $6.03(3.13)$ & 39.11 & $<.01$ & .093 \\
\hline & Sleep Variability & $2.66(2.14)$ & $4.87(2.92)$ & 12.50 & $<.01$ & .032 \\
\hline & Interaction & - & - & 2.95 & $>.05$ & .008 \\
\hline \multirow[t]{3}{*}{ Thrill and Adventure Seeking } & Sleep Duration & $4.42(3.68)$ & $7.52(2.91)$ & 31.22 & $<.01$ & .076 \\
\hline & Sleep Variability & $2.92(3.40)$ & $6.52(3.23)$ & 25.36 & $<.01$ & .062 \\
\hline & Interaction & - & - & 4.06 & $>.05$ & .011 \\
\hline \multirow[t]{3}{*}{ Experience Seeking } & Sleep Duration & $3.78(2.55)$ & $6.36(2.07)$ & 46.17 & $<.01$ & .108 \\
\hline & Sleep Variability & $2.89(2.03)$ & $5.26(2.63)$ & 19.18 & $<.01$ & .048 \\
\hline & Interaction & - & - & 3.64 & $>.05$ & .009 \\
\hline \multirow[t]{3}{*}{ Sensation Seeking } & Sleep Duration & $13.26(8.27)$ & $21.95(8.70)$ & 53.81 & $<.01$ & .124 \\
\hline & Sleep Variability & $9.88(7.39)$ & $18.57(7.70)$ & 25.71 & $<.01$ & .063 \\
\hline & Interaction & - & - & 6.02 & $<.05$ & .016 \\
\hline \multirow[t]{3}{*}{ Violence, Drug Use, and HIV Risk } & Sleep Duration & $6.39(12.11)$ & $14.82(17.56)$ & 12.30 & $<.01$ & .031 \\
\hline & Sleep Variability & $3.24(5.75)$ & $11.43(16.50)$ & 10.21 & $<.01$ & .026 \\
\hline & Interaction & - & - & .213 & $>.05$ & .001 \\
\hline \multirow[t]{3}{*}{ Tobacco and Alcohol Experiences } & Sleep Duration & $9.67(10.0 .3)$ & $16.12(12.25)$ & 10.19 & $<.01$ & .026 \\
\hline & Sleep Variability & $6.63(7.50)$ & $13.99(11.70)$ & 15.86 & $<.01$ & .040 \\
\hline & Interaction & - & - & .106 & $>.05$ & $<.001$ \\
\hline \multirow[t]{3}{*}{ Anger and family conflicts } & Sleep Duration & $8.83(7.23)$ & $12.86(6.88)$ & 12.69 & $<.01$ & .032 \\
\hline & Sleep Variability & $6.04(5.00)$ & $12.17(7.67)$ & 16.04 & $<.01$ & .040 \\
\hline & Interaction & - & - & 4.52 & $<.05$ & .012 \\
\hline \multirow[t]{3}{*}{ Unhealthy diet } & Sleep Duration & $9.11(5.30)$ & $11.10(4.61)$ & 7.56 & $<.05$ & .019 \\
\hline & Sleep Variability & $7.29(4.62)$ & $11.09(5.07)$ & 8.10 & $<.01$ & .021 \\
\hline & Interaction & - & - & 7.21 & $<.05$ & .019 \\
\hline \multirow[t]{3}{*}{ Overweight and dieting } & Sleep Duration & $1.19(1.75)$ & $1.85(2.05)$ & 5.39 & $<.05$ & .014 \\
\hline & Sleep Variability & $.86(1.45)$ & $1.64(2.00)$ & 2.77 & $>.05$ & .007 \\
\hline & Interaction & - & - & 1.29 & $>.05$ & .003 \\
\hline \multirow[t]{3}{*}{ Risk behavior } & Sleep Duration & $35.18(30.79)$ & $56.75(36.97)$ & 15.55 & $<.01$ & .039 \\
\hline & Sleep Variability & $24.07(19.68)$ & $50.31(36.38)$ & 17.20 & $<.01$ & .043 \\
\hline & Interaction & - & - & 1.63 & $>.05$ & .004 \\
\hline
\end{tabular}

a. For the "sleep duration" factor, "good sleepers" refers to participants who reported at least 6 hours of sleep a night $(\mathrm{N}=312)$; for the "sleep variability" factor, it refers to participants who reported a regular sleep schedule $(\mathrm{N}=162)$; b. For the "sleep duration" factor, "poor sleepers" refers to participants who reported less than 6 hours of sleep a night ( $\mathrm{N}=73)$; for the "sleep variability" factor, it refers to participants who reported irregular sleep schedule ( $\mathrm{N}=223)$; c. Reported Fs, adjusted P-values, and effect sizes are based on the main effects in the two-way ANOVA model. P-values are adjusted using Benjamini-Hochberg's method.

In addition, the main effects of sleep variability on the three sensation-seeking subscales (i.e. Boredom Susceptibility, Thrill and Adventure Seeking, and Experience Seeking) were significant (Ps $<.01$; partial $\eta^{2} \mathrm{~s}=.032, .062$, and .048 respectively). That is to say, students who reported sleeping on an irregular schedule scored higher on the three sensation-seeking sub-scales. The main effect of sleep variability on overall risk behavior score was also significant $(\mathrm{P}<.01$; partial $\eta 2=$ .043). That means students who reported irregular sleep patterns, also reported more risky behaviors. Finally, the main effects of sleep variability on three subscales of the risk-behavior scale (i.e. Violence, Drug Use, and HIV Risk, Tobacco and Alcohol Experiences, and Unhealthy diet) but not for the overweight and dieting subscale were significant $\left(\mathrm{Ps}<.01\right.$; partial $\eta^{2} s=.026, .040$, and .021 respectively). In other words, students who reported more variable sleep patterns scored higher on the risk behavior scale and the three sub-scales.

\section{DISCUSSION}

The results showed that an insufficient and, or irregular sleep schedule was associated with risk behavior and sensation-seeking tendencies. Interestingly, compared to previous research ${ }^{6,7}$, a small percentage of students reported insufficient sleep, while most of them reported variable sleep schedules. This observation is most likely due to conditions brought on by the Covid-19 epidemic. Students were likely to have more chances to sleep at home during the Covid-19 pandemic, but their sleep 
schedules were disturbed. This hypothesis is consistent with the previous study ${ }^{43}$, indicating an improvement in sleep duration and delayed sleep timing among students during the Covid-19 pandemic.

One of the main findings of this study was the association between irregular sleep schedules with sensationseeking and risk behavior propensities in undergraduate students. To the best of our knowledge, no research has been done on the relationship between sleep variability with sensation-seeking and risk behavior tendencies in young adults. Inconsistent sleep schedule has been shown to increase the risk of problem behavior in school-aged children ${ }^{44}$. While Troxel et al. ${ }^{37}$ discovered that adolescents with a more consistent sleep pattern engage in more risky sexual behaviors than those with a more variable schedule, they also stated that lack of variability might indicate chronic inadequate sleep on both weekdays and weekends. According to one study ${ }^{45}$, sleep variability in adolescents, regardless of duration, decreases brain development in many regions, some of which are essential for behavioral inhibition and self-regulation.

The findings may be explained using Baumeister's self-regulation theory and the concept of self-depletion ${ }^{46}$. Self-control, according to the theory, requires purposeful effort sustained by cognitive resources depleted by the act of exercising focused and persistent self-control. Ego depletion is a temporary reduction in one's ability or willingness to participate in volitional activities. Sleep, according to Baumeister, Wright, and Carreon ${ }^{47}$, is critical for restoring the depleted cognitive resources. According to their findings, reports of ego depletion spiked following poor sleep quality and quantity. Barber and her colleagues ${ }^{48,49}$ proposed that sleep consistency and sufficiency are needed for improved self-regulation. They hypothesized that in addition to the restorative advantages of adequate sleep length, long-term regular sleep habits might help people develop self-regulatory capability by requiring them to exercise self-control. In a study of adolescents ${ }^{50}$, researchers related sleep deprivation to poor self-control, while they linked poor self-control to delinquency. In the present study, we propose that insufficient and irregular sleep increases students' sensation-seeking and risk-taking tendencies by causing selfdepletion and lowering self-control.

We must interpret our results in light of the study's limitations, such as the single-item self-reported measurements of sleep length and variability of sleep schedule. Although some studies have confirmed the validity of subjective self-reported sleep ${ }^{41,42}$, others ${ }^{51}$ showed poor agreement between subjective and objective sleep measures. As a result, we cannot be certain if the people who reported inadequate sleep were sleepdeprived. However, regardless of how precise these items are at measuring sleep indices, we argue that they can display the perceived length and variability of sleep. Since it is linked to essential daytime functions ${ }^{52}$, sleep perception can be as crucial as actual sleep.
The difficulty of defining the exact nature of the interactions between variables is a second limitation. The findings may also be interpreted in the opposite direction: people with high scores in sensation-seeking and risktaking may choose short sleep duration or irregular sleep patterns. As a result, the correlational nature of this study restricts its interpretation in terms of the direction of the relationship. Sleep deprivation and variability were found to be associated with increased sensation-seeking and risk-taking behaviors. Although this is in line with theoretical assumptions, we are unable to pinpoint the precise neurological or psychological mechanisms that link the two. More research is needed to determine the relative contributions of other potentially confounding physiological (e.g., functioning of prefrontal regions such as the dorsolateral prefrontal cortex), individual (e.g., personality or lifestyle), and social (e.g., social support or socioeconomic status) factors that may underpin both poor sleep and these risk-seeking tendencies.

Our results show that sleep variability and sufficiency are associated with sensation-seeking and risk behavior tendencies and their subscales. Students who have irregular and inadequate sleep have higher scores on sensation-seeking and risk-taking indicators. They are more inclined to engage in violence, rage, and family disputes. They have a higher risk of being involved in a traffic accident, use drugs, and alcohol, and are more likely to get infected with HIV. These findings, if repeated using accurate measurements, could shed light on the connection between sleep, sensation-seeking, and risktaking tendencies.

\section{REFERENCES}

1. Faria YdO, Gandolfi L, Moura LBA. Prevalence of risk behaviors in young university students. Acta Paulista de Enfermagem. 2014;27(6):591-5.

2. Yanovitzky I. Sensation seeking and alcohol use by college students: examining multiple pathways of effects. J Health Commun. 2006;11(3):269-80.

3. Wilson LC, Scarpa A. The link between sensation seeking and aggression: A meta-analytic review. Aggressive behavior. 2011;37(1):81-90.

4. Davila EP, Christ SL, Martinez AC, Lee DJ, Arheart K, LeBlanc WG et al. Young adults, mortality, and employment. Journal of occupational and environmental medicine/American College of Occupational and Environmental Medicine. 2010;52(5):501

5. Panel CC. Recommended Amount of Sleep for a Healthy Adult: A Joint Consensus Statement of the American Academy of Sleep Medicine and Sleep Research Society. Sleep. 2015;38(6):843-4.

6. Lund HG, Reider BD, Whiting AB, Prichard JR. Sleep patterns and predictors of disturbed sleep in a large population of college students. Journal of adolescent health. 2010;46(2):124-32.

7. Sarbazvatan H, Amini A, Aminisani N, Shamshirgaran SM. Sleep quality and academic progression among students of Tabriz University of Medical Sciences, Northwest of Iran. Research and Development in Medical Education. 2017;6(1):29-33.

8. Zuckerman M. Sensation seeking. The Corsini encyclopedia of psychology. 2010:1-4.

9. Killgore WD. Effects of sleep deprivation and morningness-eveningness traits on risk-taking. Psychological reports. 2007;100(2):613-26.

10. Schmidt RE, Gay P, Van der Linden M. Facets of impulsivity are differentially linked to insomnia: Evidence from an exploratory study. Behavioral sleep medicine. 2008;6(3):178-92.

11. Miller AA, Rucas SL. Sleep-wake state tradeoffs, impulsivity and life history theory. Evolutionary Psychology. 2012;10(2):147470491201000201.

12. Neria Y, Solomon Z, Ginzburg K, Dekel R. Sensation seeking, wartime 
performance, and long-term adjustment among Israeli war veterans. Personality and Individual Differences. 2000;29(5):921-32.

13. McGowan AL, Falk E, Zurn P, Bassette D, Lydon-Staley DM. Daily and momentary sensation-seeking and urgency in young adults: Associations with risk-taking and sleep. 2021.

14. Rusnac N, Spitzenstetter F, Tassi P. Chronic sleep loss and risk-taking behavior: Does the origin of sleep loss matter? Behavioral sleep medicine. 2018.

15. Tonetti L, Adan A, Caci H, De Pascalis V, Fabbri M, Natale V. Morningness-eveningness preference and sensation seeking. European Psychiatry. 2010;25(2):111-5.

16. Chung MH, Chang FM, Yang CC, Kuo TB, Hsu N. Sleep quality and morningness-eveningness of shift nurses. Journal of clinical nursing. 2009;18(2):279-84.

17. Zuckerman M. Sensation seeking: behavioral expressions and biosocial bases. In: Wright JD, editor. International Encyclopedia of the Social \& Behavioral Sciences. Second Edition ed: Elsevier; 2015. p. 607-14.

18. Womack SD, Hook JN, Reyna SH, Ramos M. Sleep loss and risktaking behavior: a review of the literature. Behavioral sleep medicine. 2013;11(5):343-59.

19. Short MA, Weber N. Sleep duration and risk-taking in adolescents: A systematic review and meta-analysis. Sleep medicine reviews. 2018;41:185-96.

20. Mantua J, Bessey AF, Mickelson CA, Choynowski JJ, Noble JJ, Burke TM, et al. Sleep and high-risk behavior in military service members: a megaanalysis of four diverse US Army units. Sleep. 2021;44(4):zsaa221.

21. Killgore WD. Sleep deprivation and behavioral risk-taking. Modulation of Sleep by Obesity, Diabetes, Age, and Diet: Elsevier; 2015. p. 279-87.

22. Satterfield BC, Killgore WD. Sleep loss, executive function, and decisionmaking. Sleep and health: Elsevier; 2019. p. 339-58.

23. Lazzari C, Shoka A, Papanna B, Rabottini M. Insomnia induced brief manic-psychoti c episodes. Sleep Med Dis Int J. 2018;2(2):27-30.

24. Wong MM, Brower KJ, Nigg JT, Zucker RA. Childhood sleep problems, response inhibition, and alcohol and drug outcomes in adolescence and young adulthood. Alcoholism: Clinical and Experimental Research. 2010;34(6):1033-44.

25. Salfi F, Lauriola M, Tempesta D, Calanna P, Socci V, De Gennaro L, et al. Effects of total and partial sleep deprivation on reflection impulsivity and risk-taking in deliberative decision-making. Nature and science of sleep. 2020;12:309.

26. Baker AE, Tashiian SM, Goldenberg D, Galván A. Neural activity moderates the association between sleep and risky driving behaviors in adolescence. Developmental Cognitive Neuroscience. 2020;43:100790.

27. Peach HD, Gaultney JF. Sleep, impulse control, and sensation-seeking predict delinquent behavior in adolescents, emerging adults, and adults. Journal of Adolescent Health. 2013;53(2):293-9.

28. Miller MB, DiBello AM, Lust SA, Meisel MK, Carey KB. Impulsive personality traits and alcohol use: Does sleeping help with thinking? Psychology of Addictive Behaviors. 2017;31(1):46.

29. Benjamini Y, Hochberg Y. Controlling the false discovery rate: a practical and powerful approach to multiple testing. Journal of the Royal statistical society: series B (Methodological). 1995;57(1):289-300.

30. Does SPSS Statistics offer multiple comparisons using the Benjamini \& Hochberg method to control the false discovery rate? 2020 [Available from: https://www.ibm.com/support/pages/node/418001.

31. Pituch KA, Stevens JP. Applied multivariate statistics for the social sciences: Analyses with SAS and IBM's SPSS: Routledge; 2015.

32. Zuckerman M, Eysenck S, Eysenck HJ. Sensation seeking in England and America: cross-cultural, age, and sex comparisons. J Consult Clin Psychol. 1978;46(1):139-49.
33. Mahvi-Shirazi M. Validity, reliability and standardization of the Zuckerman's Sensation Seeking Scale with cultural adaptations. Daneshvar Raftar. 2008;15(1):35-49.

34. Zuckerman M. Behavioral expressions and biosocial bases of sensation seeking: Cambridge university press; 1994.

35. Manna G, Faraci P, Como M. Factorial Structure and Psychometric Properties of the Sensation Seeking Scale - Form V (SSS-V) in a Sample of Italian Adolescents. Europe's Journal of Psychology. 2013;9:276-88.

36. Shafiee A. A study of Health-Promoter School Program on attitudes toward reducing high-risk behaviors and increasing students' mental health. Torbat-e Jam: Islamic Azad University 2012.

37. Hall WA, Hauck YL, Carty EM, Hutton EK, Fenwick J, Stoll K. Childbirth fear, anxiety, fatigue, and sleep deprivation in pregnant women. Journal of Obstetric, Gynecologic \& Neonatal Nursing. 2009;38(5):567-76.

38. Vgontzas AN, Fernandez-Mendoza J, Liao D, Bixler EO. Insomnia with objective short sleep duration: the most biologically severe phenotype of the disorder. Sleep medicine reviews. 2013;17(4):241-54.

39. Miley-Åkerstedt A, Hetta J, Åkerstedt T. Criteria for self-reported quantitative sleep characteristics of individuals who sought medical help for disturbed sleep-a survey of a representative sample of the Swedish population. Nature and science of sleep. 2018;10:295.

40. Gooley JJ. How much day-to-day variability in sleep timing is unhealthy? Sleep. 2016;39(2):269-70.

41. O'donnell D, Silva EJ, Münch M, Ronda JM, Wang W, Duffy JF. Comparison of subjective and objective assessments of sleep in healthy older subjects without sleep complaints. Journal of sleep research. 2009;18(2):254-63.

42. Campanini MZ, Lopez-Garcia E, Rodríguez-Artalejo F, González AD, Andrade SM, Mesas AE. Agreement between sleep diary and actigraphy in a highly educated Brazilian population. Sleep medicine. 2017;35:27-34.

43. Wright Jr KP, Linton SK, Withrow D, Casiraghi L, Lanza SM, de la Iglesia $\mathrm{H}$, et al. Sleep in university students prior to and during COVID-19 stayat-home orders. Current Biology. 2020;30(14):R797-R8.

44. Biggs SN, Lushington K, van den Heuvel CJ, Martin AJ, Kennedy JD. Inconsistent sleep schedules and daytime behavioral difficulties in school-aged children. Sleep medicine. 2011;12(8):780-6.

45. Telzer EH, Goldenberg D, Fuligni AJ, Lieberman MD, Gálvan A. Sleep variability in adolescence is associated with altered brain development. Developmental Cognitive Neuroscience. 2015;14:16-22.

46. Baumeister RF, Vohs KD, Tice DM. The strength model of self-control. Current directions in psychological science. 2007;16(6):351-5.

47. Baumeister RF, Wright BR, Carreon D. Self-control "in the wild": Experience sampling study of trait and state self-regulation. Self and Identity. 2019;18(5):494-528.

48. Barber LK, Munz DC, Bagsby PG, Powell ED. Sleep consistency and sufficiency: Are both necessary for less psychological strain? Stress and Health. 2010;26(3):186-93.

49. Barber LK, Munz DC. Consistent-sufficient sleep predicts improvements in self-regulatory performance and psychological strain. Stress and Health. 2011;27(4):314-24.

50. Meldrum RC, Barnes JC, Hay C. Sleep deprivation, low self-control, and delinquency: A test of the strength model of self-control. Journal of youth and adolescence. 2015;44(2):465-77.

51. Girschik J, Fritschi L, Heyworth J, Waters F. Validation of self-reported sleep against actigraphy. Journal of epidemiology. 2012;22(5):462-8.

52. Insana SP, Stacom EE, Montgomery-Downs HE. Actual and perceived sleep: Associations with daytime functioning among postpartum women. Physiology \& behavior. 2011;102(2):234-8. 
Appendix: Risk Behavior Scale: Factors, Items, Eigenvalues, Means (SD), and Loadings.

\begin{tabular}{|c|c|c|c|}
\hline Factors and Items & Eigenvalues & M (SD) & Load \\
\hline 1. Violence, Drug Use, and AIDS & 23.16 & $7.99(13.70)$ & \\
\hline I have taken drugs with my friends at private parties & & $.32(.88)$ & .89 \\
\hline For self-defense, I often carry a knife, brass knuckles, a blade cutter, or other weapons & & $.33(.86)$ & .84 \\
\hline I often use other people's toothbrushes & & $.13(.41)$ & .83 \\
\hline I have tried snuff and Naswar & & $.32(.88)$ & .82 \\
\hline I sometimes take pills and smoke with my friends because I don't want to chicken out & & $.39(.93)$ & .81 \\
\hline I have a special group with my friends for fights. & & $.43(.97)$ & .79 \\
\hline I have participated in several group fights with my friends. & & $.51(1.04)$ & .79 \\
\hline It is normal to use drugs in our house. & & $.17(.57)$ & .79 \\
\hline I usually like group physical combats. & & $.44(.92)$ & .78 \\
\hline At the gym, I used a shared needle to inject vitamins and supplements & & $.17(.56)$ & .75 \\
\hline In situations, I smoked with my friend to not seem a coward to them & & $.47(1.00)$ & .75 \\
\hline I have touched the blood of others several times (in fights, injuries, accidents, etc.) & & $.36(.80)$ & .75 \\
\hline I have self-harmed several times in physical combats & & $.35(.85)$ & .72 \\
\hline I am known as an aggressive person & & $.65(1.00)$ & .72 \\
\hline My friends take drugs or pills to relieve depression and mood swings. & & $.52(.96)$ & .68 \\
\hline In some situations, I have used the razor blade of others & & $.30(.70)$ & .67 \\
\hline People more often get angry with me than with others & & $.65(.95)$ & .60 \\
\hline I often intimidate my younger siblings angrily & & $.84(1.01)$ & .59 \\
\hline My friends often smoke and use snuff at university or work & & $.62(1.03)$ & .57 \\
\hline 2. Tobacco and Alcohol Experiences & 3.63 & $10.89(10.77)$ & \\
\hline I have tried alcoholic drinks & & $.97(1.30)$ & .75 \\
\hline My friends use alcoholic drinks in private & & $1.51(1.42)$ & .75 \\
\hline My friends smoke hookah in recreational places. & & $1.74(1.38)$ & .70 \\
\hline My friends have offered me a cigarette & & $1.03(1.25)$ & .69 \\
\hline I have tried hookah with fruit flavor & & $1.54(1.38)$ & .68 \\
\hline I have been offered alcoholic drinks at wedding parties & & $.95(1.15)$ & .67 \\
\hline I have tried cigarette smoking a few puffs & & $.90(1.28)$ & .66 \\
\hline I have tried alcoholic drinks that made me lose myself & & $.61(1.11)$ & .65 \\
\hline I have tried smoking a whole cigarette & & $.88(1.38)$ & .65 \\
\hline People around me have been stoned by drugs & & $.77(1.14)$ & .56 \\
\hline 3. Anger and family conflicts & 1.98 & $9.59(7.33)$ & \\
\hline At home, the irrational behaviors of my parents drive me crazy & & $1.40(1.29)$ & .75 \\
\hline I am fed up with the harsh treatment and conflict with my family & & $1.21(1.18)$ & .71 \\
\hline I have had several suicidal thoughts in the past year & & $.51(.95)$ & .70 \\
\hline I have verbal conflicts with my family members & & $1.29(1.08)$ & .66 \\
\hline My parents are strict with me. & & $1.33(1.21)$ & .61 \\
\hline Sometimes I feel like exploding with anger like a barrel of gunpowder & & $1.32(1.16)$ & .58 \\
\hline It is difficult for me to follow the rules of our house & & $1.21(1.12)$ & .56 \\
\hline When I get angry, I have no control over what I say. & & $1.33(1.16)$ & .55 \\
\hline 4. Unhealthy diet & 1.85 & $9.49(5.23)$ & \\
\hline I often eat pizza and sandwiches. & & $1.75(1.01)$ & .80 \\
\hline I always enjoy eating potato chips and chocolate as a snack. & & $2.01(1.15)$ & .73 \\
\hline I like fatty foods. & & $1.63(1.12)$ & .71 \\
\hline I do not limit the consumption of fats, sweets, and condiments & & $1.63(1.16)$ & .69 \\
\hline I like salty foods. & & $1.42(1.14)$ & .59 \\
\hline People around me believe that I eat unhealthy foods. & & $1.05(1.11)$ & .51 \\
\hline 5. Overweight and dieting & 1.37 & $1.31(1.82)$ & \\
\hline I take strict diets to lose weight. & & $.55(.84)$ & .87 \\
\hline I feel fat compared to my friends. & & $.77(1.18)$ & .85 \\
\hline
\end{tabular}

